\title{
Understanding reality television: a study of tamil television reality shows impact on audience
}

\section{DOI: http://doi.org/10.26758/9.1.8}

\author{
Sriram ARULCHELVAN
}

Address correspondence to: Sriram Arulchelvan, Department of Media Sciences, Anna University, Chennai, Tamilnadu, India, Ph.: 09-444-819-958;

E-mail: arulchelvansriram@gmail.com

\begin{abstract}
Objectives. The aim is to identify reality television audience and its preferences and also, to analyze its context, structuring and presentation styles; to analyze its impact on the audience.

Material and methods. The study employed content analysis and survey. For the content analysis, Tamil TV reality shows namely Enga Veetu Mappillai, Villa to Village, Colors Super Kids, Super Singer and Dance Jodi Dance were analyzed. People's habitual nature, usage of words/conversation with co-hosts or contestants, costumes worn, commercial elements and incorporation of dramatic elements etc. were analyzed.

An analysis of textual data collected from newspapers and internet looked at the various perspectives regarding reality television, and its effect on Tamil culture and traditions.

The survey collected feedback on various aspects related to reality shows.

Results. In order to create hype, Tamil television reality shows unrealistic/unacceptable showcase concepts, which are leading to a cultural imbalance among the audience. These programs are designed with prewritten scripts, making the program's outcome more dramatic, and enticing viewers to consume more. However, some shows namely Super Singer and Colors Super Kids provide a platform to display talents.

Conclusions. In order to preserve the cultural values, producers should employ appropriate themes/concepts, styles of presentation, dialogues, costumes, etc. and not be driven by commercial interests and viewership ratings.
\end{abstract}

Keywords: reality TV, programmes, impact, audience, reality shows.

\section{Introduction}

The defining aspect of reality TV is probably the manner in which it is shot. Reality TV, regardless of being under the form of shows taking place in a real setting with real people (much like a documentary), shoots in front of a live studio audience participating in the program, or shoots using hidden surveillance, relies on the camera, capturing everything as it happens. Reality television is a more recent genre and a very successful phenomenon of entertainment programming in India that has been growing steadily over the past years.

However, it is a matter of great concern that reality shows have deviated from what they intended to be. Reality shows have become a paradox; the reality aspect is gradually vanishing. The structure of the programs is not spontaneous anymore. The focus is more on how to portray the show as reality rather than to let the program happen as an interaction between participants.

Reality shows have become a mixed genre of television programs. The reality programs differ from cinema and other forms of content due to the aura of realism and spontaneity they invoke (Calvert, 2004, p. 56). This has been a popular trend over the past decade with the advent of many televisions solely on creating drama through a scripted sequence, making sure that the 
audience is intrigued enough not to wonder about its authenticity. Shows like Big Brother prefer to keep the scripting aspect of the show as a secret, testing the curiosity of viewers.

The evolution has not been restricted only to the creative aspects of the show. Audiences have become more capable to find out the patterns as well as the strategy that the favorite show follows. In spite of it, spectators are hooked to the reality shows. There exists a two-way interaction between the creative writers and viewers through the reality show acting as a bridge. A major debate arises about the ethical nature of such an interaction. Some say that it is a part of how the entertainment industry has grown, defending its use of techniques to toy with the audience. Others mention that such a method employed in television programs reflect a sad reality of our society. According to the critics' opinion such shows play with the emotions of viewers, using inappropriate techniques that will have a bad effect on the society, on the lives of viewers.

In this context, this study explores the various components of Tamil television reality shows and their impact on audience perception towards its culture.

The study is guided by the following objectives:

- To identify reality television audience and its preferences;

- To analyze its context, structuring and presentation styles in Tamil reality shows;

- To analyze the news media reports on the impact of reality shows on the audience.

\section{Reality Television Shows: An Overview}

As we watch, listen, and are entertained, TV programmes are revising our social and cultural writing, shifting our sensitivities, social-relationships, and associations to the natural biosphere. Earlier people have face-to-face interactions and associations, but today, they are constantly exposed to audiovisual content through television and they are associated with it. Reality shows have amalgamated into the lives of the people, being view, on one hand, as a platform for representing the society, and on the other hand, as a medium to understand oneself better. Rutenberg (2001) said, "Some have argued that reality programs should not be honored at all, lest they sully the television industry" and at one Academy meeting, also stated that "production of reality TV was referred to as "bottom feeding" that exploits the basest human instinct for voyeurism". Gerbner (1969) developed the Cultural Indicators program as part of his work with cultivation effects, to assess the television exposure impact over the viewers.

Hill $(2005$, p. 29) points out that surging popularity of the particular genre are reflected in the TRP ratings of these programs, which in turn have resulted in higher advertising revenues for the networks. The Reality programs as a genre has unique characteristics where it is promoted as audience have gone beyond a mere spectator to an active participant. In some cases, the audience is advanced further level of main characters (Andrejevic, 2004, p. 198).

Reality TV can be generally viewed under following parameters. 1. Recording of an event in lives of the individuals or group. 2. Capturing of dramatized reconstruction of real-life events. 3. And packaging the materials into an effective entertainment program, which can be later widely marketed for the Television audience (Kilborn, 1994).

Wei and Tootle (2002) defines Reality TV as a - Television Program that has the ability to stimulate real-world, real-life psychologically, emotionally and mentally challenging situations and draw out audience into reward-motivated, self-selected contests. Reality TV often focuses on providing the viewers with a chance of becoming potential players in the entertainment program. In this way Reality TV has pushed many traditional boundaries for a television program and becomes an empowering tool for audience, enabling it to become participant and influencer in the creation of media content (Papacharissi and Mendelson, 2007).

At the present situation, the younger generation participants compete at the age of five and six, at such age being psychologically more impacted by judges' remarks on their performances. $17 \%$ 
of the respondents watch reality shows for the celebrities and fraternities who make an impact on the participants, but even a stronger one on viewers in most of aspects like lifestyle, attitude, behaviour, in such manner being interested in knowing more fantasies to be observed. It would rather be that the celebrities, who contribute to commercially driving the shows, must become the role models for the mass (Malur and Lakshmikantha, 2014).

The reality television can be evaluated with following features: 1. Use of nonprofessionally trained actors, 2. Programmes are filmed in unscripted situations, 3. Given more prominence in capturing contestants' spontaneity over improvisation, 4 . With very limited level of producer/directors' creative involvement in the programme and 5. The recording of the contestants experience not limited to particular moment (Vijaykumar and Arulchelvan, 2015). In India, Zee TV pioneered in involving the audience in the elimination process of contestants of the program, Cine Stars Ki Khoj meaning "Search for a film star". This elimination process has been later replicated by many reality television and celebrity based programmes. Soon after many new methods have undertaken to improvise the voting process, by initiating new 'one mobile-one vote' type campaign in different shows, to avoid duplication of audience votes, as well as new 'Missed call voting' system, a phenomenon that helps the audience to participate and vote free of cost.

\section{Material and methods}

The study employed both content analysis and questionnaire based survey. For the content analysis of the reality shows, the following Tamil TV reality shows were included: Enga Veetu Mappillai, Villa to Village, Colors Super Kids, Super singer, and Dance Jodi Dance. Each of the five programs was watched by the researcher/coder. Prior to watching the programs, the researcher identified the major thematic elements, that were relatable to the cultural impacts such as people's habitual nature, usage of words/conversation with co-hosts or contestants, costumes worn, commercial elements and incorporation of dramatic elements etc. Those themes were independently coded, based on the total amount of time each of the thematic element has consumed on screen time.

The secondary sources involved textual data, which were collected from newspaper articles, internet sources regarding such programmes. The articles were coded/ transcribed based on the source, context, and relationship with the current study. The analysis looked at the various perspectives/opinions regarding the reality television, exhibiting the dual nature of reality show and its effect on the Tamil culture and traditions.

In addition to the content analysis, the questionnaire survey collected the feedback from the respondents on various aspects related to the reality shows. The mode of answering was restricted only to the online medium.

\section{Results}

The study mainly focuses on examining the impact of Tamil television reality shows on culture. Totally 240 respondents participated in the survey questionnaire. The result pertaining to the survey-based approach aids in understanding the youths' inclination to reality shows.

Table 1. Time Spent on Watching Television in a Day

\begin{tabular}{|l|c|}
\hline Watching in Hours & Percentage (\%) \\
\hline Less than 1 Hour & 34.2 \\
\hline $1-2$ Hours & 42.1 \\
\hline $3-4$ Hours & 15 \\
\hline More than 4 Hours & 1.2 \\
\hline
\end{tabular}


The above table shows that nearly half $(46 \%)$ of the respondents have the habit of watching TV for more than 1-2 hours, followed by $37 \%$ respondents who are watching TV programmes for less than one hour. Only $16 \%$ of the respondents have the habit of watching TV programmes for more than 4 hours.

Table 2. Respondents' Choice of Tamil Channels

\begin{tabular}{|l|c|}
\hline Channel Name & $(\%)$ \\
\hline Star Vijay & 58.8 \\
\hline Sun TV & 11.3 \\
\hline Zee Tamil & 7.1 \\
\hline Colors Tamil & 6.3 \\
\hline Others & 16.5 \\
\hline
\end{tabular}

The above table shows the respondents' choice of watching Tamil television channels. $58.8 \%$ of the respondents watch Star Vijay compared to other Tamil television channels like Sun TV, Zee Tamil and Colors Tamil. Some respondents prefer Tamil channels being telecasted by the cable operators and not distributed throughout Tamil Nadu.

Table 3. Various sources through which respondents get to know about those reality shows

\begin{tabular}{|l|c|}
\hline Category & $(\%)$ \\
\hline Advertisement & 46.3 \\
\hline Word of Mouth & 16.7 \\
\hline Publicity & 22.1 \\
\hline Promos on YouTube & 13.3 \\
\hline Others & 1.6 \\
\hline
\end{tabular}

Most $(46.3 \%)$ of the respondents get to know about those television reality shows through the advertisements and promos. $22 \%$ of the respondents feel that the publicity given by the television channel also plays a crucial role in the viewer's engagement with the reality shows.

Table 4. Do you agree that the content and the style of presentation of Tamil television reality shows are causing cultural imbalance among the audience?

\begin{tabular}{|l|c|}
\hline Response & $\%$ \\
\hline Yes & 28.7 \\
\hline No & 27.5 \\
\hline May Be & 43.8 \\
\hline
\end{tabular}

From the above table, we can see that the majority of the respondents $(43.8 \%)$ were inconclusive with their opinion. It is probably because a few shows are innovative, unlocks new talents among the participants and tries to promote traditional cultural values. Respondents of equal numbers $(27.5 \%$ and $28.7 \%)$ tend to have conflicting opinions with their agreement on the reality shows and its impact on cultural values.

Table 5. Respondents' views on the scripting styles used in production of reality shows

\begin{tabular}{|l|c|}
\hline Response & $\%$ \\
\hline Full scripted & 29 \\
\hline Semi scripted & 58 \\
\hline Spontaneous & 11 \\
\hline Poorly scripted & 2 \\
\hline
\end{tabular}


The majority (58\%) of the respondents view the scripting styles of the reality shows to be semi-scripted. To ensure higher viewers rating for the programme, the producers use scripted elements in terms of dialogues, costume, talent behavior and creating situations to make the program more dramatic and sensational for the audience and thus totally deviating from the principle of reality element which is the essence of reality shows. $29 \%$ of the respondents feel that the reality shows were fully scripted, greatly deviating from the reality elements in this manner, while $11 \%$ of the respondents feel there is complete spontaneity in the show and realism exhibit in the programmes.

Table 6. Elements that attract respondents' attention in watching reality shows

\begin{tabular}{|l|c|}
\hline Response & $\%$ \\
\hline Concepts & 49 \\
\hline Presenting styles & 25 \\
\hline Host & 11 \\
\hline Celebrity guest & 15 \\
\hline
\end{tabular}

Respondents were asked to choose the elements that attract their attention in watching the Tamil television reality shows. Among the various choices given to them, the respondents were mainly influenced by the programme's concepts/idea (49\%), followed by programme's presenting style $(25 \%)$, celebrity guest $(15 \%)$ and host $(11 \%)$. The results show that overall idea/concept is the most important element in attracting the audience attention in reality shows rather than other elements.

Table 7. Respondents' interest towards participation in reality shows

\begin{tabular}{|l|c|}
\hline Response & $\%$ \\
\hline Yes & 18.7 \\
\hline No & 45 \\
\hline May Be & 36.3 \\
\hline
\end{tabular}

The above table shows that the majority $(45 \%)$ of the respondents denied their interest in participating in reality shows. Some $(36.3 \%)$ respondents were inconclusive about participating in the reality shows. Only $18.7 \%$ of the respondents were willing to participate in reality shows.

Table 8. Respondents' most favorite Tamil television reality shows

\begin{tabular}{|l|c|}
\hline Response & Percentage \\
\hline Super singer & 68 \\
\hline Color super kids & 16 \\
\hline Enga veetu mappilai & 4 \\
\hline Villa to village & 12 \\
\hline
\end{tabular}

The majority of the respondents showed greater interest in the reality show titled Super Singer (68\%), followed by Colors Super kids (16\%), Villa to Village (12\%) and Enga Veetu Mapillai (4\%). 


\section{Discussions}

Content analysis was carried out including both the video programs and textual data extracted from newspaper/online articles reported on Tamil television reality shows. The study analyzed the five different reality shows, which were monitored over a period of 1 month (January to February 2018). In this study, the content analysis focuses mainly on the following prominent elements namely:

- Role of prewritten scripts in reality shows

- Usage of words/dialogues in the program

- Participants' usage of props/costumes (western/traditional wears),

- Influence of media advertising on reality shows

- The necessity for viewers' discretion

Table 9. The below table shows the total number of articles/internet sources on reality shows that are analyzed for this study

\begin{tabular}{|l|l|l|l|l|l|}
\hline No. & $\begin{array}{l}\text { Names of the } \\
\text { selected reality } \\
\text { Shows }\end{array}$ & $\begin{array}{l}\text { No. of } \\
\text { articles on } \\
\text { poor scripting } \\
\text { /usage } \\
\text { concepts }\end{array}$ & $\begin{array}{l}\text { No. of articles } \\
\text { targeting on the } \\
\text { program's } \\
\text { scripts } \\
\text { /concepts to be } \\
\text { exposing } \\
\text { cultural values }\end{array}$ & $\begin{array}{l}\text { No. of articles } \\
\text { targeting on } \\
\text { the program's } \\
\text { scripts / } \\
\text { concepts, } \\
\text { affecting the } \\
\text { cultural values }\end{array}$ & $\begin{array}{l}\text { Total number } \\
\text { of articles on } \\
\text { reality shows }\end{array}$ \\
\hline 1 & $\begin{array}{l}\text { Enga veetu } \\
\text { Maapillai }\end{array}$ & 4 & 0 & 12 & 16 \\
\hline 2 & Villa to Village & 2 & 4 & 7 & 13 \\
\hline 3 & Super Singer & 5 & 19 & 1 & 25 \\
\hline 4 & Colors Super Kids & 1 & 18 & 0 & 19 \\
\hline
\end{tabular}

\section{Role of prewritten scripts in reality shows}

The content analysis of newspaper articles/online forums indicated that in most of these reality shows, the scripts were prewritten before the shooting for the purpose of dramatizing the real events. Therefore, the audiences wonder whether the particular programme content is real or fake. The media reports also criticized the quality of scripts used in the programs.

\section{Usage of words/dialogues in the program}

In reality shows, the usage of dialogue by the contestants, hosts and judges play a crucial role in audience engagement in the programme. Programmes as Enga Veetu Mapillai, Villa to Village portray intense dramatic scenarios among the participants through the usage of dialogues. It is noticed that the use of harsh words, inappropriate dialogues, and bullying comments were showcased or highlighted in order to create hype among the audience. On the contrary, the programmes Super Singer and Colors Super Kid were exhibiting the participants' talents, where the dialogues/usage of words for creating a hype or viewer's rating was not required. 


\section{Participants' usage of props/costumes (western/traditional wears)}

In many cases, the participants, as well as the celebrities, were using western outfits over traditional dresses. Reality shows like Enga Veetu Mappilai and Villa to Village tend to adopt more of westernized outfits for presenting the shows. In certain episodes, the costumes that were worn by the female participants were inappropriate and deviate from the Tamil cultural values. In case of reality shows like Colors Super Kids and Super Singers, the participants, hosts and judges were wearing both traditional and western costumes that were appropriate and professional.

\section{The influence of reality show teaser on the audience}

It is observed that the reality shows teaser has a significant effect on the people, as they show the gist of the sequence that exposes dramatic events, which makes the people to emotionally feel sympathetic/bad regarding that particular situation. However, the concern is in some cases the situations shown were depressing and cultureless. For instance, in Enga Veetu Maapillai, the way some of the scenes portrayed reality was totally against the cultural and moral values followed in Tamil tradition. The sequence showing the lead actor trying to impress many women and vice versa was found to be disturbing to the audience. In the reality show Villa to Village, the women contestants, exchanging harsh and sensitive words and behaving in a harsh way appears quite unpleasant for the viewers to watch.

\section{Viewers' discretion in watching the reality shows}

Viewers' discretion is becoming necessary in watching reality shows. Majority of the reality shows concepts and themes are suited mainly for the adults and are quite unacceptable for the children and teenagers to view as it might affect them psychologically. This could be witnessed in programs like Enga Veetu Mapillai and Villa to Village. Certain scenes involve inappropriate romancing, usage of harsh and vulgar words, which could affect the children's psyche and development. Hence viewers' discretion is becoming a necessity for watching reality shows.

\section{Conclusions}

In order to create hype among the audience, Tamil television reality shows are employing certain unrealistic and unacceptable concepts, which are causing a certain degree of cultural imbalance among the audience. Those reality programmes are designed primarily with prewritten scripts, thus making the programme's outcome more dramatic and arousing the curiosity of the viewers to eagerly wait for the forthcoming episode. However, on a positive side, some reality shows are focusing primarily on unleashing the participant's talents and showcasing it to the public. Tamil television reality shows namely Super Singer and Colors Super Kids provide an opportunity for the common man to showcase his or her talent to the audience. Thus, the study could be concluded with a positive remark that, in order to preserve the cultural values in the Tamil television reality shows, the producers should employ appropriate themes/concepts, style of presentation, dialogues and costumes in the programs and at the same time they should not allow the commercial interest and viewer ratings to drive the program content and style of presentation. 


\section{Bibliography}

1. Andrejevic, M., 2004. Reality TV: The work of being watched. Lanham, MD: Rowman \& Littlefield Publishers.

2. Calvert, C., 2004. Voyeur nation: Media, privacy, and peering in modern culture (Critical Studies in Communication and in Cultural Industries), Boulder, CO: Westview Press.

3. Gerbner, G., 1969. Toward "cultural indicators": The analysis of mass mediated public message systems. AV communication review, 17(2), pp.137-148.

4. Hill, A., 2005. Reality TV: Television Audiences and Popular Factual Entertainment. New York \& London: Routledge.

5. Kilborn, R., 1994. 'How real can you get?': Recent developments in Reality' television. European Journal of Communication, [e-journal] 9(4), pp.421-439, https://doi.org/10.1177/0267323194009004003.

6. Kosovski, J.R. and Smith, D.C., 2011. Everybody hurts: Addiction, drama, and the family in the reality television show intervention. Substance Use \& Misuse, [e-journal] 46(7), pp.852858, https://doi.org/10.3109/10826084.2011.570610.

7. Vijaykumar, V. and Arulchelvan, S., 2015. Motivation and impact of viewing reality television programme: An audience study. Indian Journal of Science and Technology, [ejournal] 8(27), http://dx.doi.org/10.17485/ijst\%2F2015\%2Fv8i27\%2F71556.

8. Malur, P.G. and Lakshmikantha, D., 2014. Reeling the Reality: A study on contemporary Reality Shows and their Influence on other Entertainment Program Genres. International Research Journal of Social Sciences, 3(8), pp.1-3.

9. Papacharissi, Z. and Mendelson, A.L., 2007. An exploratory study of reality appeal: Uses and gratifications of reality TV shows. Journal of Broadcasting \& Electronic Media, 51(2), pp.355-370.

10. Rutenberg, J. (2001, February 12). Reality shows set off fight over awards. The New York Times, p. C1.

11. Wei, R. and Tootle, C., 2002. Gratifications of reality viewing: Antecedents and consequences. A paper presented to the Entertainment Studies Division of the AEJMC (Association for Education in Journalism and Mass Communication), Miami Beach, FL August 2002. 